\title{
SYNOPSES
}

\section{THE INTERMEDIARY'S DILEMMA: ASSESSING THE FINANCIAL STRENGTH OF LIFE OFFICES}

\author{
By M. Ljeskovac, B.Sc., Ph.D., F.F.A., D. M. Nisbet, B.Sc., F.F.A. \\ AND J. A. Ross, M.A., F.F.A.
}

(Synopsis of a paper presented to the Society on 1 December 1987)

UNDER the Financial Services Act, individuals and institutions providing investment advice have to fulfil the 'best advice' requirements. Assuming that a with-profit type of contract is appropriate for a client, the intermediary will have to consider the relative merits of different life offices. The paper concentrates on financial strength and discusses a particular approach to its assessment on the basis of published information.

The intermediary's dilemma is that he has a duty to consider a life office's strength in relation to its competitors before recommending it to a client, but there is no simple and reliable means of performing this duty. There are two levels of financial strength:

- as a measure of the ability of a life company to meet its contractual liabilities, and

-as a measure of a life company's future bonus-earning potential.

The paper is concerned with the second definition of financial strength, although clearly an office able to meet the reasonable bonus expectations of its policyholders will not go into liquidation.

The intermediary's task is not simplified by the publicly-available information. The annual reports and accounts contain little that is relevant. The DTI returns are more useful and provide details of assets, liabilities and solvency margins in Forms 9 and 14 of Schedule 1. However, these published figures do not provide a satisfactory means of comparing financial strength of different companies: although assets are valued on a broadly consistent basis, the valuation of liabilities is unlikely to be consistent, both among different offices and within the same office for different years.

There is no perfect solution to the problem and no single figure which ranks life companies in order of financial strength, but a general picture of each company can be built by examining a number of measures.

The suggested approach is that of a standardized valuation for all companies, on the basis of published information. A realistic estimate is first made of free reserves, defined as the difference between the market value of the assets and the 
value of guaranteed liabilities (i.e. including bonuses declared to date, but not future bonuses). This amount can be expressed as a percentage of the market value of assets.

Next, the present value of future reversionary bonuses at present rates on the in-force business is established, and the free reserves less this amount are compared with the market value of assets.

Finally, the free reserves, less the value of future reversionary bonuses on the in-force business, are compared with the support required to allow the latest year's new business to pay current rates of reversionary bonus.

Other relevant factors are discussed, including shareholders' participation (if any), new business trends, expense ratios, underwriting standards, investment strategy, financial guarantees, and transfers from investment reserves.

The methodology is based on the mutualization price techniques first developed in the late 1960's for evaluating proprietary life companies. The basis for calculations is Schedule 5 of the DTI returns, updated as necessary to take into account subsequent movements. Together with other schedules, it allows a reasonably full picture of the life company's products and portfolios to be formed. However, other sources of information are necessary as well, such as trade journals. The valuation itself is a gross premium one, with realistic mortality, interest and other assumptions. Various problems arise: timing of the DTI returns, deficiencies in the information provided, and treatment of subsidiaries.

Finally, an example is given of the results of the calculations for three life offices.

\section{COMMERCIAL FIRE INSURANCE}

By N. R. Gillot et al.

(Synopsis of a paper presented to the Society on 5 January 1988)

IN 1847 W. E. Hillman, Actuary to the Star Assurance Office, stated that "the time is approaching when ... the present loose and almost undefined method of estimating (fire insurance) premiums for different kinds of risks will give place to one of a more scientific and definite nature". However, since that time, the actuary's role in fire insurance has been negligible and it could be argued that the setting of commercial fire insurance premiums is still not undertaken in a scientific way. The authors believe that actuarial techniques are very relevant to this problem. The paper aims to introduce the subject of fire insurance and to indicate areas in which actuaries might be usefully involved. The timing of the paper is opportune as many offices are having to produce their own premium 